\title{
Depression and Anxiety Disorders in Patients with Hyperemesis Gravidarum and the Effect of This Disease on the Quality of Life
}

\author{
Dilşad Herkiloğlu* and Şefik Gökçe \\ Obstetrics and Gynecology Department, Private Gaziosmanpaşa Hospital, Yeni Yüzyıl University \\ Gaziosmanpaşa, Turkey
}

\begin{abstract}
Introduction: Hyperemesis gravidarum can lead to depression or anxiety disorder in pregnant women more frequently than serious complications. This situation can significantly deteriorate the quality of life of the pregnant woman. In our study, it was aimed to investigate the levels of depression and anxiety in patients with hyperemesis gravidarum, and to analyze the effect of hyperemesis on quality of life.

Methods: The study included 87 patients diagnosed with hyperemesis and 24 patients without hyperemesis. All participants received Beck Anxiety Inventory, Beck Depression Inventory and 12-question quality of life (SF-12) forms.

Results: Minimal minimal anxiety and depression were detected in all participants. There was no significant difference between the group of patients diagnosed with hyperemesis and the control group in terms of mean depression score $(p=0.161)$ and anxiety score $(p=0.266)$. No significant difference was found in terms of the distribution of depression and anxiety levels between the groups ( $p=0.46$ and $p=0.557$, respectively). Discussion and Conclusion: In conclusion, our findings show that anxiety and depression levels cannot be directly correlated with hyperemesis gravidarum. However, it is necessary to closely monitor the psychological status of pregnant women diagnosed with hyperemesis, to perform the necessary supportive treatments and to improve their quality of life.
\end{abstract}

Keywords

Hiperemezis gravidarum, Beck Anksiyete Envanteri, Beck Depresyon Envanteri, SF-12

\section{Introduction}

Nausea and vomiting during pregnancy is a common condition. Nausea occurs in $50-90 \%$ of pregnant women in the first trimester period. It has been reported that the cause of nausea in pregnancy is increased human chorionic gonadotrop hormone (HCG) level [1-3]. Hyperemesis gravidarum is a stubborn and severe clinical picture with nausea and vomiting. Nutritional disorders, dehydration, electrolyte disorders, weight loss and catatonia can also be added to this manifestation. Hyperemesis gravidarum, which can be seen in $0.5-2 \%$ of pregnant women, may be at a grade that may require hospitalization of some patients [1-5].

Although it has been stated that factors such as increased beta-HCG level, steroids, multiple pregnancy, increase in body mass index and hyperemesis gravidarum history may play a role in the development of the hyperemesis gravidarum manifestation, the exact cause has not been determined [1,5-7]. In some cases with severe hyperemesis gravidarum,serious complications such as Wernicke's encephalopathy and thromboembolism can be seen in the mother, and low birth weight, preterm delivery, developmental delay, some anomalies and mortality can be observed in the fetus. Therefore, rapid supportive therapy is important in hyperemesis gravidarum [4-7].

Hyperemesis gravidarum can also lead to depression or anxiety disorder in pregnant women more frequently than serious complications. This situation can significantly

*Corresponding author: Dilşad Herkiloğlu, Obstetrics and Gynecology Department, Private Gaziosmanpaşa Hospital, Yeni Yüzyıl University Gaziosmanpaşa, Istanbul/Turkey, Tel: 054228423742

Accepted: July 26, 2021

Published online: July 28, 2021

Citation: Herkiloğlu D, Gökçe S (2021) Depression and Anxiety Disorders in Patients with Hyperemesis Gravidarum and the Effect of This Disease on the Quality of Life. J Depress Anxiety Disord 3(2):101-105 
Citation: Herkiloğlu D, Gökçe S (2021) Depression and Anxiety Disorders in Patients with Hyperemesis Gravidarum and the Effect of This Disease on the Quality of Life. J Depress Anxiety Disord 3(2):101-105

deteriorate the quality of life of the pregnant woman. ${ }^{[6-8]}$ In our study, it was aimed to investigate the levels of depression and anxiety in patients with hyperemesis gravidarum and to analyze the effect of hyperemesis on quality of life.

\section{Materials and Methods}

This study was approved by the local ethics committee and was planned prospectively.

\section{Patients}

The study group included 87 patients up to 20 weeks of gestation diagnosed with hyperemesis between the ages of 17 and 39 who applied to the gynecology outpatient clinics of our hospital. A total of 24 patients without hyperemesis was included in the study as the control group. Pregnant women with single live pregnancy accompanied by ketosis accompanied by recurrent nausea, vomiting, and dehydration findings were included in the study, and those with additional systemic disease, smokers, signs of infection, those with a pre-diagnosis of abortus imminens, and those with fetal congenital malformation were excluded. The gestational age of the patients was determined using the first day of the last menstrual period and was confirmed by ultrasonography.

\section{Scales}

Turkish versions of Beck Depression Scale and Beck Anxiety Scale were used to determine the depression and anxiety states of pregnant women. In both scales, questionnaire forms consisting of 21 questions were used and scoring between 0-63 was applied. High score meant more severe depression or anxiety. ${ }^{[11,12]}$ Physical and mental scoring was done for pregnant women using SF-12 (Short Form 36, Questionnaire of Evaluating Life Quality) life quality form consisting of 12 questions.

\section{Statistical analysis}

All statistical analyzes in the study were done using SPSS 25.0 software (IBM SPSS, Chicago, IL, USA). Descriptive data are given as numbers and percentages. In terms of categorical variables, comparisons between groups were made with Pearson's Chi Square test and Fisher's Exact Test. Whether continuous variables are suitable for normal distribution was confirmed by the Kolmogorov-Smirnov Test. The differences between the groups in terms of continuous variables were made using Student's $t$ Test and the comparison of mean values between multiple groups by variance analysis. The relationship between continuous variables was tested using Spearman's correlation analysis. The results were evaluated within the $95 \%$ confidence interval and $p<0.05$ values were considered significant. Bonferroni correction was made where appropriate.

\section{Results}

The mean age of the patients included in the study was $25.4 \pm 5.0$ years (Age range: 17-39 years). The mean gestational week was $10.3 \pm 4.0$ weeks (range: $4-27$ weeks).

At least minimal anxiety and depression were detected in all participants. No signficant differences were found between the hyperemesis and the control groups in terms of mean age $(p=0.194)$, gestational week $(p=0.082)$, number of gravida $(p=0.506)$, number ofparity $(p=0.949)$, depression score $(p$ $=0.161)$, anxiety score $(p=0.266)$, physical score $(p=0.684)$ and mental score $(p=0.263)$ (Table 1$)$.

Severe depression was detected in seven (8.0\%) patients in the hyperemesis group and two (8.3\%) patients in the control group. Severe anxiety was detected in $14(16.1 \%)$ patients in the hyperemesis group and in three (12.5\%) patients in the control group. No significant difference was found in the distribution of depression and anxiety levels between the groups ( $p=0.46$ and $p=0.557$, respectively) (Table 2 ).

In the correlation analysis, both depression and anxiety scores were found to be negatively correlated with SF-12 mental score $(p<0.001 ; r=-0.538$ and $p<0.001 ; r=-0.539$, respectively) and physical score $(p<0.001 ; r=-0.426$ and $p$ $<0.001 ; r=-0.436$, respectively) in the hyperemesis group (Table 3).

\section{Discussion}

Hyperemesis gravidarum is a clinical picture that can be caused by many endocrinological, psychosocial or biochemical factors. Although it does not occur very frequently in pregnant women, it may be at a grade that affects the quality of life in some pregnant women. Constant and severe nausea and vomiting can make pregnancy much more difficult, which even leads to unusual changes itself $[1,2,6,8]$.

Table 1: Comparison of mean values of various variables between groups.

\begin{tabular}{|l|c|c|c|c|c|}
\hline \multirow{2}{*}{} & \multicolumn{2}{|c|}{ Hyperemesis } & \multicolumn{2}{c|}{ Control } & \multirow{2}{*}{ p } \\
\cline { 2 - 5 } & Mean & SD* & Mean & SD & \\
\hline Age & 25.8 & 4.8 & 24.3 & 5.4 & 0.194 \\
\hline Gestational week & 10 & 3.7 & 11.6 & 4.9 & 0.082 \\
\hline Gravida & 1.9 & 0.8 & 2 & 1 & 0.506 \\
\hline Parity & 0.7 & 0.8 & 0.7 & 0.8 & 0.949 \\
\hline Depression score & 15.4 & 9.2 & 12.4 & 9.7 & 0.161 \\
\hline Anxiety score & 15.1 & 9.1 & 12.7 & 9.6 & 0.266 \\
\hline Physical score & 42.1 & 7.7 & 42.8 & 9.4 & 0.684 \\
\hline Mental score & 43.1 & 10.5 & 45.8 & 11.3 & 0.263 \\
\hline
\end{tabular}

Table 2: Comparison of depression and anxiety severity distributions between groups.

\begin{tabular}{|c|c|c|c|c|c|c|c|}
\hline & \multicolumn{2}{|c|}{ Hyperemesis } & \multicolumn{2}{|c|}{ Control } & \multicolumn{2}{|c|}{ Total } & \multirow{2}{*}{ p } \\
\hline & $\mathrm{n}$ & $\%$ & $\mathbf{n}$ & $\%$ & $\mathbf{n}$ & $\%$ & \\
\hline \multicolumn{7}{|c|}{ Depression level } & 0.46 \\
\hline Minimal & 28 & 32.2 & 11 & 45.8 & 39 & 35.1 & \\
\hline Mild & 24 & 27.6 & 7 & 29.2 & 31 & 27.9 & \\
\hline Moderate & 28 & 32.2 & 4 & 16.7 & 32 & 28.8 & \\
\hline Severe & 7 & 8.0 & 2 & 8.3 & 9.0 & 8.1 & \\
\hline Total & 87 & 100 & 24 & 100 & 111 & 100 & \\
\hline \multicolumn{7}{|c|}{ Anxiety level } & 0.557 \\
\hline Minimal & 20 & 23.0 & 9 & 37.5 & 29 & 26.1 & \\
\hline Mild & 32 & 36.8 & 7 & 29.2 & 39 & 35.1 & \\
\hline Moderate & 21 & 24.1 & 5 & 20.8 & 26 & 23.4 & \\
\hline Severe & 14 & 16.1 & 3 & 12.5 & 17 & 15.3 & \\
\hline Total & 87 & 100 & 24 & 100 & 111 & 100 & \\
\hline
\end{tabular}


Citation: Herkiloğlu D, Gökçe S (2021) Depression and Anxiety Disorders in Patients with Hyperemesis Gravidarum and the Effect of This Disease on the Quality of Life. J Depress Anxiety Disord 3(2):101-105

Table 3: Correlation analysis between anxiety and depression scores and SF-12 mental and physical scores in Hyperemesis gravidarum group.

\begin{tabular}{|l|c|c|c|}
\hline & Depression & Anxiety score \\
\hline \multirow{2}{*}{ Physical score } & $\mathbf{r}$ & -0.426 & -0.436 \\
\cline { 2 - 4 } & $\mathbf{p}$ & $<0.001$ & $<0.001$ \\
\hline \multirow{2}{*}{ Mental score } & $\mathbf{r}$ & -0.538 & -0.539 \\
\cline { 2 - 4 } & $\mathbf{p}$ & $<0.001$ & $<0.001$ \\
\hline
\end{tabular}

It has been reported that pregnant women with hyperemesis gravidarum may develop depression and/or anxiety [9-13]. However, whether anxiety and depression is the result or cause of the hyperemesis gravidarum picture has not been definitively determined [14,15]. Aksu, et al.[16] reported that hyperemesis had a psychiatric background in their study. However, London, et al. [1] reported in their extensive meta-analysis that anxiety and depression were not the cause, but the result, of hyperemesis gravidarum. Seng, et al. [9] and Fell, et al. [10] reported that hyperemesis gravidarum was diagnosed with a significantly higher rate of psychiatric disorders in pregnant women. Simpson, et al. [17] also supported this finding and reported that psychiatric disorder resolved with the end of pregnancy. Simsek, et al. [15], Yildirim, et al. [18] and Erginbas-Kender, et al.[11] found significant depression and anxiety scores in pregnant women with hyperemesis gravidarum in their studies conducted in Turkey. Similarly, Özen, et al.[12], Tan, et al.[13] and Kasap [16] found that hyperemesis gravidarum was associated with depression and anxiety in their studies. Topalahmetoglu, et al. [19] found that mean anxiety and depression scores were significantly higher in the hyperemesis group, and this was attributed to the socioeconomic status and the education level of the family. In our study, no significant difference was found between the groupsin terms of the mean scores of both depression and anxiety. These differences among the studies may be due to differences in socioeconomic, educational and social relationship levels between the groups created in some studies. In other words, when the tables of the studies are examined, it can be seen that the groups could not be formed socio-demographically equivalent, and that anxiety and depression may be due to these differences rather than hyperemesis. All these data show that hyperemesis gravidarum can lead to depression and anxiety during pregnancy, but due to the wide range of factors, the situation can be variable in every pregnant woman, and in addition, the situation of depression and anxiety should be monitored carefully in pregnant women without hyperemesis.

According to the findings of the study conducted by Özen, et al. [12], the rate of severe anxiety in pregnant women diagnosed with hyperemesis gravidarum was significantly higher than the control group, and the rate of minimal anxiety level was significantly lower $(p<0.001$; as the result of statistical analysis performed by us based on the data of that paper). According to the same study data, there was no difference between the groups in terms of distribution of depression levels ( $p=0.06$; as the result of statistical analysis performed by us based on the data of that paper). In our study, the groups were similar in terms of both depression and distribution of anxiety levels. These data show that the presence of anxiety and/or depression may be associated with hyperemesis gravidarum, as well as the level of anxiety and depression may be differentin pregnant women with hyperemesis. These findings show that pregnant women with hyperemesis should be closely monitored in terms of the presence of anxiety or depression, as well as the levels of these clinical pictures.

Özen, et al. [12] determined that $96 \%$ of pregnant women diagnosed with hyperemesis gravidarum had at least minimal anxiety, and $88 \%$ had at least minimal depression. In our study, all pregnant women diagnosed with hyperemesis had at least minimal depression and anxiety. These data show that the presence of depression and/or anxiety with hyperemesis table does not differ from the control groups, as well as that there are very high rates of depression and anxiety in these pregnant women. Therefore, not only the women with hyperemesis but alsoall pregnant women should be evaluated in terms of depression and anxiety.

Hyperemesis gravidarum may occur in some pregnant women due to pre-pregnancy psychiatric findings [3-5,20]. Uguz, et al. [20] found that the rate of pre-pregnancy psychiatric disorder history was significantly higher in pregnant women diagnosed with hyperemesis gravidarum, and stated that this was a factor that might lead to the development of hyperemesis in pregnant women. ErginbasKender, et al. [11] did not find a significant difference between hyperemesis gravidarum and the control groups in terms of the presence of a history of psychiatric disorder. In our study, the prevalence rate of symptoms of psychiatric disorders before pregnancy was found similar in both groups. These data show that the findings related to the psychiatric condition before pregnancy in some pregnant women may be related to the hyperemesis gravidarum during pregnancy, but the clinical picture may be different in each pregnant woman.

It has been stated that hyperemesis gravidarum may be related with some-sociodemographic characteristics of pregnant woman [1,6,21]. Kamalak, et al. [21], Simsek, et al. [15] and Kasap [14] found that the number of parity history was significantly lower in pregnant women with hyperemesis compared to the control group. Erginbas-Kender va ark [11] also found that pregnant women with hyperemesis gravidarum had significantly lower numbers of parity and gravida in their studies. However, Özen, et al. [12], Türkmen, et al. [22] and Beyazit, et al. [23] reported that there was no significant differences between hyperemesis and the control groups in terms of numbers of parity and gravida in their studies. In our study, no significant difference was found between hyperemesis gravidarum and control groups in terms of meannumbers of parity and gravida. These data show that hyperemesis gravidarum may develop more frequently in those with less pregnancy experience, but that hyperemesis can also be seen frequently in some pregnant women who have more pregnancy experience.

The effect of the hyperemesis gravidarum on the quality of life can also be measured using SF-36 and its shortened version, SF-12, questionnaires, where physical and mental scores can be evaluated $[23,24]$. Tan, et al. [25] found the 
Citation: Herkiloğlu D, Gökçe S (2021) Depression and Anxiety Disorders in Patients with Hyperemesis Gravidarum and the Effect of This Disease on the Quality of Life. J Depress Anxiety Disord 3(2):101-105

physical and mental scores in all pregnant women in the range of $40-50 \%$, and found that the mean mental score in the hyperemesis group was significantly lower than the control group. Munch, et al. [26] found mental and physical scores in the range of $35-43 \%$ in their studies, and reported a significantly lower mean score in the hyperemesis group compared to the control group. In our study, physical and mental scores in all pregnant women were in the range of $40-50 \%$, and there was no significant difference between hyperemesis and control groups in terms of both physical and mental mean scores. These data show that mental and physical scores are below the middle levels in all pregnant women. However, in the correlation analysis conducted in our study, both depression and anxiety scores were found to be negatively correlated with SF-12 mental and physical scores in the hyperemesis group. This finding shows that as the levels of anxiety and depression increase, the mental and physical score and therefore the quality of life decreasein pregnant women with hyperemesis.

There were some limitations in our study. Since our study was a cross-sectional study, the post-pregnancy status of the pregnant women was not followed, and it was not possible to evaluate whether the hyperemesis gravidarum was related to preterm birth, low birth weight or postpartum depression. In our study, since the hyperemesis level was not classified, it could not be analyzed whether the factors examined had an effect on the hyperemesis level.

\section{Conclusion}

our study data show that anxiety and depression levels cannot be directly associated with hyperemesis gravidarum. However, it is necessary to closely monitor the psychological status of pregnant women diagnosed with hyperemesis, to perform necessary supportive treatments and to improve their quality of life.

\section{Source of support}

None.

\section{Conflicts if Interests}

None to declare.

\section{Criteria for Inclusion of the Authors}

Contributors who have met with one or more of the followings have been accepted as the authors: Concept, design, definition of intellectual content, literature search, clinical studies, experimental studies, data acquisition, data analysis, statistical analysis, manuscript preparation, manuscript editing and manuscript review.

\section{References}

1. London V, Grube S, Sherer DM, et al. (2017) Hyperemesis gravidarum: A review of recent literature. Pharmacology 100: 161-171.

2. Dean CR, Shemar M, Ostrowski GAU, et al. (2018) Management of severe pregnancy sickness and hyperemesis gravidarum. BMJ 363: k5000.
3. Abramowitz A, Miller ES, Wisner KL (2017) Treatment options for hyperemesis gravidarum. Arch Womens Ment Health 20: 363-372.

4. Dean CR, Bruin CM, O'Hara ME, et al. (2019) The chance of recurrence of hyperemesis gravidarum: A systematic review. Eur J Obstet Gynecol Reprod Biol X 5: 100105.

5. Austin K, Wilson K, Saha S (2019) Hyperemesis Gravidarum. Nutr Clin Pract 34: 226-241.

6. Tamay AG, Kuscu NK (2011) Hyperemesis gravidarum: Current aspect. J Obstet Gynaecol 31: 708-712.

7. Ioannidou P, Papanikolaou D, Mikos T, et al. (2019) Predictive factors of Hyperemesis Gravidarum: A systematic review. Eur J Obstet Gynecol Reprod Biol 238: 178-187.

8. Yanikkerem E, Ildan Calim S, Göker A, et al. (2012) Opinions and needs of pregnant women with hyperemesis gravidarum. Gümüshane University Journal of Health Sciences 1: 269-283.

9. Seng JS, Schrot JA, van De Ven C, et al. (2007) Service use data analysis of pre-pregnancy psychiatric and somatic diagnoses in women with hyperemesis gravidarum. J Psychosom Obstet Gynaecol 28: 209-217.

10. Fell DB, Dodds L, Joseph KS, et al. (2006) Risk factors for hyperemesis gravidarum requiring hospital admission during pregnancy. Obstet Gynecol 107: 277-284.

11. Erginbas Kender E, Yüksel G, Ger C, et al. (2015) Eating attitudes, depression and anxiety levels of patients with hyperemesis gravidarum hospitalized in an obstetrics and gynecology clinic. Düsünen Adam The Journal of Psychiatry and Neurological Sciences 28: 119-126.

12. Özen O, Mihmanli V, Cetinkaya N, et al. (2013) Evaluation of anxiety and depression in hyperemesis gravidarum patients. Okmeydani Tip Dergisi 29: 143-146.

13. Tan PC, Vani S, Lim BK, et al. (2010) Anxiety and depression in hyperemesis gravidarum: prevalence, risk factors and correlation with clinical severity. Eur J Obstet Gynecol Reprod Biol 149: 153-158.

14. Kasap E (2018) Depression And Anxiety Test Scores In patients with hyperemesis gravidarum. Selcuk Med J 34: 155-159.

15. Simsek Y, Celik Ö, Yilmaz E, et al. (2012) Assesment of anxiety and depression levels of pregnant women with hyperemesis gravidarum in a case-control study. J Turkish-German Gynecol Assoc 13: 32-36.

16. Aksu E, Albayrak Y, Beyazyüz E, et al. (2019) Distinct temperament and character traits in patients with hyperemesis gravidarum. Gynecol Endocrinol 36: 525-529.

17. Simpson SW, Goodwin TM, Robins SB, et al. (2001) Psychological factors and hyperemesis gravidarum. J Womens Health Gend Based Med 10: 471-477.

18. Yildirim E, Demir E (2019) The relationship of hyperemesis gravidarum with sleep disorders, anxiety and depression. J Obstet Gynaecol 39: 793-798.

19. Topalahmetoglu Y, Altay MM, Akdag Cirik D, et al. (2017) Depression and anxiety disorder in hyperemesis gravidarum: $A$ prospective case-control study. Turk J Obstet Gynecol 14: 214219.

20. Uguz F, Gezginc K, Kayhan F, et al. (2012) Is hyperemesis gravidarum associated with mood, anxiety and personality disorders: A case-control study. Gen Hosp Psychiatry 34: 398-402. 
Citation: Herkiloğlu D, Gökçe S (2021) Depression and Anxiety Disorders in Patients with Hyperemesis Gravidarum and the Effect of This Disease on the Quality of Life. J Depress Anxiety Disord 3(2):101-105

21. Kamalak Z, Kösüs N, Kösüs A, et al. (2013) Is there any effect of demographic features on development of hyperemesis gravidarum in the Turkish population? Turk J Med Sci 43: 995-999.

22. Türkmen H (2019) The effect of hyperemesis gravidarum on prenatal adaptation and quality of life: A prospective casecontrol study. J Psychosom Obstet Gynaecol 41: 282-289.

23. Hoffman DL, Dukes EM (2008) The health status burden of people with fibromyalgia: A review of studies that assessed health status with the SF-36 or the SF-12. Int J Clin Pract 62: 115-126.
24. Wood H, McKellar LV, Lightbody M (2013) Nausea and vomiting in pregnancy: Blooming or bloomin' awful? A review of the literature. Women Birth 26: 100-104.

25. Tan A, Lowe S, Henry A (2018) Nausea and vomiting of pregnancy: Effects on quality of life and day-to-day function. Aust N Z J Obstet Gynaecol 58: 278-290.

26. Munch S, Korst LM, Hernandez GD, et al. (2011) Health-related quality of life in women with nausea and vomiting of pregnancy: The importance of psychosocial context. J Perinatol 31: 10-20. 